\title{
Effects of Sevelamer and Calcium-Based Phosphate Binders on Lipid and Inflammatory Markers in Hemodialysis Patients
}

\author{
Ronney Shantoufa Matthew J. Budoffa Naser Ahmadi ${ }^{a}$ Jima Tiano ${ }^{a}$ \\ Ferdinand Flores $^{\mathrm{a}}$ Kamyar Kalantar-Zadeh ${ }^{\mathrm{b}}$ \\ Divisions of a Cardiology and ${ }^{b}$ Nephrology, Los Angeles Biomedical Research Institute at Harbor-UCLA, \\ Torrance, Calif., USA
}

\section{Key Words}

End-stage renal disease - Cardiac computed tomography •

Coronary calcium $\cdot$ Phosphate binders

\begin{abstract}
Introduction: Cardiovascular disease accounts for almost half of all deaths in individuals with chronic kidney disease stage 5 despite advances in both dialysis treatment and cardiology. A combination of lipid-lowering and anti-inflammatory effects along with avoidance of hypercalcemia should be taken into account when choosing phosphorus binders for maintenance hemodialysis (MHD) patients. Methods: We examined the association of sevelamer versus calciumbased phosphorus binders with lipid profile, inflammatory markers including C-reactive protein (CRP), and mineral metabolism in MHD patients who participated in the Nutritional and Inflammatory Evaluation of Dialysis Patients (NIED) study from October 2001 to July 2005. Results: Of the 787 MHD patients in the NIED study, 697 were on either sevelamer, a calcium-based binder, or both and eligible for this study. We compared the groups based on taking sevelamer monotherapy ( $n=283$ ) or calcium binder monotherapy ( $n=266$ ) for serum phosphate control. There were no differences between the groups on dialysis vintage. There were significant differences in age, serum calcium and phosphorus levels, as well as intact parathyroid hormone levels.
\end{abstract}

Using a logistic regression models, the sevelamer group had a higher odds of serum CRP $<10 \mathrm{mg} / \mathrm{l}$ [odds ratio (OR): 1.06, 95\% Cl: 1.02-1.11] and LDL cholesterol <70 mg/dl (OR: 1.33, 95\% Cl: 1.19-1.47) when compared to the calcium binder group independent of age, vintage, body mass index, statin use or other variables. Conclusion: The improvements in multiple surrogate markers of inflammation and lipids in the NIED study make sevelamer a promising therapy for treatment in MHD patients with high risk of cardiovascular disease and mortality.

Copyright $\odot 2007$ S. Karger AG, Basel

\section{Introduction}

Cardiovascular (CV) disease accounts for almost half of all deaths in individuals with chronic kidney disease (CKD) stage 5, also known as end-stage renal disease (ESRD), despite advances in both dialysis treatment and cardiology [1]. CV mortality among ESRD patients is 10to 30 -fold greater than among the general population regardless of gender, age, race, and presence of diabetes [1]. In the general population, the increased risk of atherosclerotic CV disease, which is associated with elevated LDL cholesterol and triglycerides and decreased HDL cholesterol, is usually managed by low-fat diet, HMGCoA reductase inhibitors (statins) and niacin therapy,

\section{KARGER}

() 2007 S. Karger AG, Basel

Fax +41613061234 E-Mail karger@karger.ch www.karger.com www.karger.com/ajn
Matthew J. Budoff, MD

Los Angeles Biomedical Research Institute at Harbor-UCLA

1124 W. Carson Street, RB2

Torrance, CA 90502 (USA)

Tel. +1 310222 4107, Fax +1 310787 0448, E-Mail mbudoff@labiomed.org 
among others [2-4]. Whereas these modalities may reduce the burden of $\mathrm{CV}$ disease in the general population, their role in ESRD patients is not clear and studies are mixed. Inflammation is a strong correlate of atherosclerotic CV disease and death in both the general population and CKD patients $[5,6]$. Inflammatory markers such as circulating C-reactive protein (CRP) and interleukin-6 (IL-6) are predictive of coronary artery disease in the general population [7] and are correlated with poor outcomes in the CKD population $[6,8,9]$. Studies suggest that in maintenance hemodialysis (MHD) patients a paradoxical association exists between low serum cholesterol and increased all-cause and CV death [4, 10-12].

Homocysteine and uremia have also been associated with poor outcomes in this population $[13,14]$. Hypercalcemia and hyperphosphatemia are associated with increased risk of coronary artery calcification in ESRD [15, 16]. As a result, serum phosphorus $>5.5 \mathrm{mg} / \mathrm{dl}$, albuminadjusted calcium level $>9.5 \mathrm{mg} / \mathrm{dl}$, and increased calcium-phosphorus product $>55 \mathrm{mg}^{2} / \mathrm{dl}^{2}$ are to be avoided in MHD patients, as recommended by the National Kidney Foundation Kidney Disease Outcome Quality Initiative guidelines [15]. Hence, improving hyperphosphatemia in MHD patients with non-calcium-based phosphorus binders may be advantageous. Sevelamer, a nonabsorbable non-calcium-based hydrogel, has been shown in recent randomized trials of ESRD patients to decrease CRP, total and LDL cholesterol, and slow the progression of coronary artery calcification when compared to calcium acetate [18-21]. In this study we examined the effects of sevelamer versus calcium-based phosphorus binders on lipid profile, inflammatory markers such as CRP, tumor necrosis factor- $\alpha$ (TNF- $\alpha$ ), IL-6, and mineral metabolism $(\mathrm{Ca}, \mathrm{Ca} \times \mathrm{P})$, among other markers in a real-world population of MHD patients who participated in the ongoing Nutritional and Inflammatory Evaluation of Dialysis Patients (NIED) study from 10/2001 to 7/2005.

\section{Methods}

\section{Patients}

All 787 patients who were enrolled in the NIED study from $10 / 2001$ to $7 / 2005$ were screened in this study. The NIED study (www.NIEDstudy.org) is an ongoing prospective cohort study to determine whether nutritional and inflammatory states in dialysis populations affect mortality, morbidity, and other clinical outcomes. Inclusion criteria for the NIED study include patients who were 18 years or older and who signed a written consent. Patients with malignancy or other terminal diseases with less than a 6 month life expectancy were excluded. The subjects were all receiving MHD via high-flux dialyzers, and their dialysis mem- branes were routinely reused. New subjects were recruited on a quarterly basis and followed for up to 5 years or 10 semiannual rounds with each round consisting of a semiannual assessment of malnutrition and inflammatory variables including biochemical markers, anthropometric measurements, hospitalization rates, and mortality. Medical chart review, including comorbidities and outpatient medication usage were performed on all new recruits and then on a yearly basis thereafter. Round 1 (initial recruitment round) data for the enrolled 787 subjects was used to assess the subject's use of phosphate binders, statins, and concurrent biochemical markers.

All subjects upon initial round 1 recruitment for the NIED study underwent medical chart review by an MD to evaluate for current outpatient medication usage. This available data was used to determine if a subject was on a calcium- or non-calcium-based binder. Calcium-based binders included: calcium carbonate, calcium acetate and other forms of calcium such as Os-Cal (GlaxoSmithKline), non-calcium-based binders included only sevelamer-hydrochloride. Some subjects were on none or both types of binders. Statin usage was also documented for all subjects.

\section{Dialysis and Laboratory Data}

The single-pool Kt/V was used to represent the weekly dialysis dose of each subject. Vintage time was calculated based on the time between first dialysis date and beginning of round 1 upon quarterly enrollment. Serum levels of calcium, phosphorus, parathyroid hormone $(\mathrm{PTH})$, and albumin were obtained through routine laboratory measurements performed by DaVita Laboratories (DeLand, Fla., USA) using automated methods. Average values for each laboratory test within the 13-week period, coinciding with the study round and calendar quarter, were calculated and used for the data analysis in the study. For this study, data originating from the first round was used for calculations.

\section{Study Laboratory Tests}

Serum CRP and two proinflammatory cytokines (IL-6, TNF$\alpha$ ), serum cholesterol, LDL and HDL cholesterol, as well as homocysteine levels were measured from fasting samples in all patients. The high-sensitivity CRP was measured by a turbidimetric immunoassay where a serum sample is mixed with latex beads coated with anti-human CRP antibodies forming an insoluble aggregate (WPCI, Osaka, Japan; normal range $<3.0 \mathrm{mg} / \mathrm{l}$ ) [22]. Highsensitivity IL- 6 and TNF- $\alpha$ immunoassay kits based on a solid-phase sandwich enzyme-linked immunosorbent assay using recombinant human IL- 6 and TNF- $\alpha$ are used to measure the serum proinflammatory cytokines (R\&D Systems, Minneapolis, Minn., USA; normal range IL-6, $<9.9$ pg/ml; TNF- $\alpha,<4.7$ pg/ml) [23].

\section{Statistics}

Conventional analysis of variance, Kruskal-Wallis test, and $\chi^{2}$ were used, as appropriate, to detect significant differences among groups using sevelamer and calcium-based binders. Multivariate regression analyses and analysis of covariance were performed to obtain adjusted $\mathrm{p}$ controlled for case-mix and comorbidity covariates. Case-mix covariates included sex (female), age, race (black versus other), and dialysis vintage (number of months on MHD treatment). Comorbidity covariates included diabetes mellitus (yes/no), history of CV disease (yes/no), statin use (yes/no). Laboratory covariates in fully adjusted multivariate models in- 
Table 1. Demographic and laboratory data of the binder groups in the NIED study (means \pm SD for continuous variables)

\begin{tabular}{|c|c|c|c|}
\hline Variables & $\begin{array}{l}\text { Sevelamer } \\
\text { group } \\
(\mathrm{n}=283)\end{array}$ & $\begin{array}{l}\text { Calcium } \\
\text { binder group } \\
(\mathrm{n}=266)\end{array}$ & $\begin{array}{l}\mathrm{p} \\
\text { value }\end{array}$ \\
\hline Age, years & $51 \pm 14$ & $55 \pm 13$ & 0.0001 \\
\hline Gender (men) & $49 \%$ & $43 \%$ & 0.14 \\
\hline Ethnicity (Hispanic) & $47 \%$ & $55 \%$ & 0.07 \\
\hline Race (African-American) & $35 \%$ & $28 \%$ & 0.06 \\
\hline Dialysis vintage & & & 0.86 \\
\hline$<6$ months & $20 \%$ & $21 \%$ & \\
\hline $6-24$ months & $55 \%$ & $55 \%$ & \\
\hline$\geq 24$ months & $25 \%$ & $24 \%$ & \\
\hline $\mathrm{Kt} / \mathrm{V}$ & $1.6 \pm 0.26$ & $1.59 \pm 0.31$ & 0.82 \\
\hline Intact PTH, pg/ml & $375 \pm 359$ & $239.4 \pm 192.3$ & 0.0001 \\
\hline Albumin, g/dl & $3.92 \pm 0.35$ & $3.87 \pm 0.34$ & 0.054 \\
\hline Calcium, mg/dl & $9.55 \pm 0.66$ & $9.25 \pm 0.57$ & 0.0001 \\
\hline Phosphorus, mg/dl & $6.01 \pm 1.37$ & $5.47 \pm 1.28$ & 0.0001 \\
\hline $\mathrm{CRP}, \mathrm{mg} / \mathrm{l}$ & $4.6 \pm 4.1$ & $5.9 \pm 5.6$ & 0.005 \\
\hline Homocysteine, $\mu \mathrm{mol} / \mathrm{l}$ & $23.65 \pm 9.3$ & $23.17 \pm 7.46$ & 0.5 \\
\hline Total cholesterol, mg/dl & $137.3 \pm 37.5$ & $154.5 \pm 42.8$ & 0.0001 \\
\hline $\mathrm{HDL}, \mathrm{mg} / \mathrm{dl}$ & $36.6 \pm 12.5$ & $35 \pm 11.9$ & 0.3 \\
\hline $\mathrm{LDL}, \mathrm{mg} / \mathrm{dl}$ & $74.8 \pm 27.2$ & $94.3 \pm 34.3$ & 0.0001 \\
\hline Triglyceride, mg/dl & $150.3 \pm 90.1$ & $154 \pm 85.7$ & 0.75 \\
\hline IL-6, pg/l & $14.3 \pm 6.8$ & $13.1 \pm 7$ & 0.53 \\
\hline TNF- $\alpha, p g / d l$ & $8.09 \pm 8$ & $8.3 \pm 8$ & 0.82 \\
\hline
\end{tabular}

cluded blood hemoglobin, homocysteine, CRP, IL-6, TNF- $\alpha$, and albumin concentrations, as well as all lipid variables and mineral metabolism measures including $\mathrm{PTH}$, calcium, and phosphorus levels. Risk ratios include $95 \%$ confidence intervals (CI); p less than 0.05 or a $95 \%$ CI that did not span 1.0 is considered statistically significant; $\mathrm{p}$ between 0.05 and 0.20 also is listed with two decimals for the sake of potential type II errors. Descriptive and multivariate statistics were carried out using the statistical software Stata, version 9.0 (Stata Corp., College Station, Tex., USA).

\section{Results}

Of the 787 MHD patients in the study, 697 were on either sevelamer or a calcium-based binder, or both. The mean $( \pm \mathrm{SD})$ age of the 697 patients was $53 \pm 14$ years. There were 369 male and 328 female patients; 223 patients were African-American and 353 were Hispanic. The majority of patients were on dialysis for 6-24 months (52.6\% of patients); 334 patients were diabetic. The average body mass index (BMI) was $26.2 \pm 5.5$. We then compared the groups based on taking sevelamer monotherapy $(n=283)$ or calcium binder monotherapy $(n=266)$. There were no differences between the groups on vintage
Table 2. Odds ratio (OR) of CRP $<10 \mathrm{mg} / \mathrm{l}$ for sevelamer versus calcium binder

\begin{tabular}{lll}
\hline Logistic regression models $^{1}$ & OR (95\% CI) & p value \\
\hline $1 \quad$ Unadjusted & $1.05(1.01-1.08)$ & 0.020 \\
2 Case-mix adjusted & $1.05(1.01-1.09)$ & 0.018 \\
$3 \quad+$ statin & $1.05(1.01-1.09)$ & 0.018 \\
$4 \quad+$ Kt/V, albumin, minerals, iPTH & $1.06(1.02-1.11)$ & 0.004 \\
\hline
\end{tabular}

${ }^{1}$ Covariates include: model 1 = no covariates; model 2 = age, gender, vintage, diabetes, ethnicity, race and BMI; model 3 = age, gender, vintage, diabetes, ethnicity, race and BMI, statin use; model $4=$ age, gender, vintage, diabetes, ethnicity, race and BMI, statin use, Kt/v, intact PTH (iPTH), albumin, calcium, phosphorus.

Table 3. Odds ratio (OR) of LDL $<70 \mathrm{mg} / \mathrm{dl}$ for sevelamer versus calcium binder group

\begin{tabular}{|c|c|c|}
\hline Logistic regression covariates $^{1}$ & OR (95\% CI) & $p$ value \\
\hline Unadjusted & $1.26(1.15-1.37)$ & 0.0001 \\
\hline Case-mix & $1.27(1.15-1.38)$ & 0.0001 \\
\hline $3+$ statin & $1.27(1.15-1.38)$ & 0.0001 \\
\hline $4+\mathrm{Kt} / \mathrm{V}$, albumin, minerals, $\mathrm{PTH}$ & $1.33(1.18-1.43)$ & 0.0001 \\
\hline
\end{tabular}

${ }^{1}$ Covariates include: model 1 = no covariates; model 2 = age, gender, vintage, diabetes, ethnicity, race and BMI; model 3 = age, gender, vintage, diabetes, ethnicity, race and BMI, statin use; model 4 = age, gender, vintage, diabetes, ethnicity, race and BMI, statin use, Kt/V, intact PTH, albumin, calcium, phosphorus.

dialysis. There were significant differences in age, mean serum calcium and phosphorus levels, as well as PTH levels. Furthermore, there was a significant difference in CRP, total cholesterol, and LDL (table 1).

After multivariate analysis, the sevelamer group still demonstrated a lower CRP (OR: 1.06, 95\% CI: 1.02-1.11) when compared to the calcium binder group when adjusted for age, gender, vintage, diabetes mellitus, BMI, statin use, and other noted cofounders (table 2). Similarly, the sevelamer group also had a lower serum LDL $<70$ mg/dl (OR: 1.33, 95\% CI: 1.19-1.47) when comparing to the calcium binder group with similar adjustments for confounders (table 3). These differences remained significant after multivariate analysis for all relevant covariates. Other serum markers measured, such as IL-6, TNF$\alpha$, and homocysteine, were not found to be different between groups. 


\section{Discussion}

Unique to their population, MHD patients exhibit nontraditional risk factors contributing to their high incidence of $\mathrm{CV}$ disease, including malnutrition as reflected by hypoalbuminemia and low protein intake [24], anemia and iron deficiency [25], and bone and mineral disorders such as hyperphosphatemia, hypercalcemia, hyperparathyroidism and vitamin $\mathrm{D}$ deficiency [26]. The vast majority of ESRD patients are on some form of a phosphorus binder to lower intestinal phosphorus absorption and its serum levels. While effective at lowering phosphorus and the calcium-phosphorus product, other pleiotropic effects of these binders have been described including effects on lipid profiles, inflammatory states, and uric acid. Recent studies have suggested sevelamer may specifically lower the inflammatory burden, and favorably adjust lipid profiles in the ESRD patients [1821].

Our results indicate that MHD patients treated with sevelamer monotherapy were more likely to have a lower LDL, CRP, and total cholesterol, as compared to patients treated with calcium-based binder monotherapy. At the same time, there was no difference in other inflammatory markers such as IL- 6 and TNF- $\alpha$ between those on sevelamer and calcium-based binders.

While this was not a randomized controlled trial, it does present real-world data of ESRD patients and does correlate with results of randomized trials such as the Treat to Goal Study [19-21]. The data presented here represent a 'real-life' treatment of ESRD patients, different than almost all previous studies of calcium binders, in that we did not control for any other variable. Prior studies of the effect of sevelamer and other binders have controlled for phosphate levels, creating a somewhat artificial environment to study the effect of these therapies, since most practice patterns do not revolve solely around control of one variable in ESRD patients. This study, as a purely observational study, reinforces that these effects still occur, even when the drug is not titrated carefully to control for one or two variables.

Do calcium-free binders, such as sevelamer, have a role in treating hyperlipidemia, and should they be used with the goal in mind to lower the 'inflammatory state' of a CKD patient? Studies with statins in this population have been disappointing. The 4-D trial, which evaluated the efficacy of lipid lowering in over 1,200 diabetic MHD patients by randomizing patients to placebo or atorvastatin (20 mg/day), did demonstrate lower LDL in the statin group versus the placebo group, although the study did not show a statistically significant improvement in CV events and mortality in the LDL-lowering arm as compared to the placebo arm [12]. Whether the LDL-lowering of sevelamer translates into improved outcomes in this population will need further evaluation.

The improvement in multiple surrogate markers (lipids, inflammation) makes this approach a promising therapy for treatment of a population of patients with very high CV mortality and high burden of dyslipidemia and inflammation. Of note, the DCOR study [27] demonstrated a nonsignificant $9 \%$ reduction in mortality in those patients treated with sevelamer compared to binders; with subgroups treated beyond 2 years, there was a $34 \%$ reduction $(\mathrm{p}=0.02)$. There was a significant interaction by age: those over 65 years had a significant $22 \%$ reduction in all-cause mortality (RR $0.78, \mathrm{p}=0.03$ ), whereas those under 65 had no significant benefit $(\mathrm{p}=0.42)$. Those on sevelamer therapy longer ( $>2$ years) also had significant mortality benefits, similar to timelines demonstrating mortality benefits with statins over longer treatment timelines (3-5 years). Another recent study demonstrated a greater risk of death for patients treated with calcium-containing phosphate binders (hazard ratio 3.1, CI 1.23-7.61) [28]. The collection of mortality and morbidity data is currently continued in our NIED study and will help delineate whether or not binders have a role in survival or quality of life in our cohort.

In conclusion, our study showed a salutary lipid-lowering and anti-inflammatory effect of sevelamer as compared to calcium-based binders. Certainly, a combination of lipid effects and mineral effects must be taken into account when choosing a binder for patients presenting with hyperphosphatemia. Combined therapy with both types of binders may prove most prudent to control mineral metabolic effects of ESRD as well as modifiable CV risk factors. Further larger studies will be needed to better delineate the role of binders in treating $\mathrm{CV}$ disease in ESRD patients.

\section{Acknowledgments}

We are thankful to Ms. Stephanie Griffith, at Harbor-UCLA General Clinical Research Center (GCRC) Core Laboratories for the management of blood samples and measuring inflammatory markers. This study was supported by a National Institutes of Health, National Institute of Diabetes, Digestive and Kidney Disease Grant no. K23-DK61162, a research grant from Genzyme, Inc., and a GCRC grant no. M01-RR00425 from the National Centers for Research Resources, National Institutes of Health. 


\section{References}

1 Foley RN, Parfrey PS, Sarnak MJ: Clinical epidemiology of cardiovascular disease in chronic renal disease. Am J Kidney Dis 1998; 32(suppl 3):S112-S119.

$\checkmark 2$ Third Report of the National Cholesterol Education Program (NCEP) Expert Panel on Detection, Evaluation, and Treatment of High Blood Cholesterol in adults (Adult Treatment Panel III) final report. Circulation 2002;106:3143.

$\checkmark 3$ Prichard SS: Impact of dyslipidemia in endstage renal disease. J Am Soc Nephrol 2003; 14:S315-S320.

$\checkmark 4$ Kilpatrick RD, McAllister CJ, Kovesdy CP, Derose SF, Kopple JD, Kalantar-Zadeh K: Association between serum lipids and survival in hemodialysis patients and impact of race. J Am Soc Nephrol 2007;18:293-303.

$\checkmark 5$ Stenvinkel P, Alvestrand A: Inflammation in end-stage renal disease: sources, consequences, and therapy. Semin Dial 2002;15: 329-337.

-6 Wanner C, Zimmermann J, Schwedler S, et al: Inflammation and cardiovascular risk in dialysis patients. Kidney Int Suppl 2002;80: 99-102.

$\checkmark 7$ Ridker PM: Clinical application of C-reactive protein for cardiovascular disease detection and prevention. Circulation 2003;107: 363-369.

$\checkmark 8$ Arici M, Walls J: End-stage renal disease, atherosclerosis, and cardiovascular mortality: is C-reactive protein the missing link? Kidney Int 2001;59:407-414.

-9 Owen WF, Lowrie EG: C-reactive protein as an outcome predictor for maintenance hemodialysis patients. Kidney Int 1998;54: 627-636.

-10 van den Akker JM, Bredie SJ, Diepenveen $\mathrm{SH}$, et al: Atorvastatin and simvastatin in patients on hemodialysis: effects on lipoproteins, C-reactive protein and in vivo oxidized LDL. J Nephrol 2003;16:238-244.

-11 Seliger SL, Weiss NS, Gillen DL, et al: HMGCoA reductase inhibitors are associated with reduced mortality in ESRD patients. Kidney Int 2002;61:297-304.
12 Wanner C, Krane V, Marz W, et al: Atorvastatin in patients with type 2 diabetes mellitus undergoing hemodialysis. N Engl J Med 2005;353:238

13 Bostom AG, Lathrop L: Hyperhomocysteinemia in end-stage renal disease: prevalence, etiology, and potential relationship to arteriosclerotic outcomes. Kidney Int 1997;52: $10-20$.

14 Nishizawa Y, Shon T, Kawagishi T, Morii H: Atherosclerosis in uremia: possible roles of hyperparathyroidism and intermediate density lipoprotein accumulation. Kidney Int 1997;52(suppl 62):S90-S92.

15 Block GA, Hulbert-Shearon TE, Levin NW, Port FK: Association of serum phosphorus and calcium $\times$ phosphate product with mortality risk in chronic hemodialysis patients: a national study. Am J Kidney Dis 1998;31:601-617.

-16 Kalantar-Zadeh K, Block G, Humphreys $\mathrm{MH}$, Kopple JD: Reverse epidemiology of cardiovascular risk factors in maintenance dialysis patients. Kidney Int 2003;63:793808.

17 National Kidney Foundation: K/DOQI clinical practice guidelines for chronic kidney disease: evaluation, classification, and stratification. Am J Kidney Dis 2002;39(suppl 1): S1-S266.

18 Raggi P, Boulay A, Chasan-Taber S, Amin N, Dillon M, Burke SK, Chertow GM: Cardiac calcification in adult hemodialysis patients: a link between end-stage renal disease and cardiovascular disease? J Am Coll Cardiol 2002;39:695-701.

19 Chertow GM, Burke SK, Raggi P, et al: Sevelamer attenuates the progression of coronary and aortic calcification in hemodialysis patients. Kidney Int 2002;62:245-252.

20 Chertow GM, Burke SK, Dillon MA, et al: Long-term effects of sevelamer hydrochloride on the calcium-phosphate product and lipid profile of haemodialysis patients Nephrol Dial Transplant 1999; 14:29072914.
21 Ferramosca E, Burke S, Chasan-Taber S, Ratti C, Chertow G, Raggi P: Potential antiatherogenic and anti-inflammatory properties of sevelamer in maintenance hemodialysis patients. Am Heart J 2005; 149:820-825.

22 Ridker PM, Rifai N, Rose L, Buring JE, Cook NR: Comparison of C-reactive protein and low-density lipoprotein cholesterol levels in the prediction of first cardiovascular events. N Engl J Med 2002;347:1557-1565.

23 Kalantar-Zadeh K, McAllister CJ, Lehn RS, Lee GH, Nissenson AR, Kopple JD: Effect of malnutrition-inflammation complex syndrome on EPO hyporesponsiveness in maintenance hemodialysis patients. Am J Kidney Dis 2003;42:761-773.

-24 Shinaberger CS, Kilpatrick RD, Regidor DL, McAllister CJ, Greenland S, Kopple JD, Kalantar-Zadeh K: Longitudinal associations between dietary protein intake and survival in hemodialysis patients. Am J Kidney Dis 2006;48:37-49.

25 Regidor DL, Kopple JD, Kovesdy CP, Kilpatrick RD, McAllister CJ, Aronovitz J, Greenland S, Kalantar-Zadeh K: Associations between changes in hemoglobin and administered erythropoiesis-stimulating agent and survival in hemodialysis patients. J Am Soc Nephrol 2006;17:1181-1191.

-26 Kalantar-Zadeh K, Kuwae N, Regidor DL, Kovesdy CP, Kilpatrick RD, Shinaberger CS, McAllister CJ, Budoff MJ, Salusky IB, Kopple JD: Survival predictability of time-varying indicators of bone disease in maintenance hemodialysis patients. Kidney Int 2006;70:771-780

27 Suki W, Zabaneh R, Cangiano J, et al: The DCOR trial? A prospective, randomized trial assessing the impact on outcomes of sevelamer in dialysis patients (abstract THPO745). Renal Week, Philadelphia, Nov 2005

28 Block GA, Raggi P, Bellasi A, Kooienga L, Spiegel DM: Mortality effect of coronary calcification and phosphate binder choice in incident hemodialysis patients. Kidney Int 2007;71:438-441. 